\title{
Malaria - The Formidable Enemy of Humanity
}

\author{
Anil Pawar ${ }^{1, a^{*}}$, Amit Pal $^{2, b}$ \\ ${ }^{1}$ Department of Zoology, DAV University, Jalandhar-144012 (India) \\ ${ }^{2}$ Department of Biochemistry, PGIMER, Chandigarh-160012 (India) \\ E-mail address: asumanil27@yahoo.co.in \\ bmaximus1134@gmail.com
}

Keywords: Malaria, Plasmodium, clinical manifestations, economy

\begin{abstract}
Malaria, a disease caused by protozoan parasite of the genus Plasmodium, is an ancient enemy of the human race. Despite enormous efforts to control, it is still a main cause of morbidity and mortality in many endemic countries of the world, particularly Africa, South of Sahara. Malaria seems to be unstoppable due to lack of an effective vaccine, acquisition of drugresistance by malaria parasite, and insecticide resistance by Anopheles mosquitoes. In this scenario, along with search for novel preventive approaches, adequate health facilities, health literacy and awareness among people are required to control and eliminate this formidable disease from society.
\end{abstract}

\section{HISTORICAL PERSPECTIVE}

Malaria is one of the most life-threatening ancient parasitic diseases, causing great morbidity and mortality in many developing countries. It is probably one of the oldest diseases and supposedly had its origins in the jungles of Africa, where it is still very much rampant. Man and malaria seem to have evolved together. References of this disease can be found in the ancient Chinese, Indian and Egyptian manuscripts. The history of malaria dates back to the prehistoric times and the documented history began as early as in 1600 B.C. in ancient Egypt. Hippocrates in 400 B.C. was the first to classify intermittent fever along with other characters of the disease. Previously, malaria was known by various names like jungle fever, intermittent and remittent fever and marsh fever etc. The disease was named malaria by Macculoch in 1827 on the idea that it was caused by filthy air of marshy regions [1].

Alfonse Laveran, a French army medical officer in Algeria in 1880, first of all discovered the malarial parasite in an unstained preparation of wet blood smear of a patient [2]. In 1892, a German doctor, Richard Pfeiffer proposed the role of some sanguivorous insect in malaria transmission. Sir Patrick Manson (1894) was the first to suggest the role of mosquitoes in spreading of malaria [3]. Sir Ronald Ross (1898) discovered the complete sporogony of Plasmodium relictum, a blood malaria parasite in Culex pipiens fatigans [4]. The sporogony of Plasmodium falciparum [5], Plasmodium vivax and Plasmodium malariae [6] was also recognized in Anopheles mosquito. Exoerythrocytic schizogony of Plasmodium elongatum in tissue cells was described by Raffaele (1934) [7]. Shortt and Garnham (1948) reported the pre-erythrocytic cycle of Plasmodium cyanomolgi [8] and P. vivax; whereas, that of P. falciparum was discovered by Shortt et al. (1951) [9].

\section{CURRENT STATUS}

Malaria is still a major global health problem despite the extensive research in the development of novel antimalarial drugs, vaccines and insecticides. It is responsible for nearly 250 million new clinical cases resulting about 1.2 million deaths annually, the majority of which are caused by $P$. falciparum [10]. In 2012, out of the 104 endemic countries, seventy-nine are classified as being in the malaria control phase, ten are in the pre-elimination phase, and 10 are in elimination phase. Besides this, five countries are in the prevention of re-introduction phase as these are without ongoing transmission. Approximately 3.3 billion people were at risk of malaria in 2011 worldwide; 
mostly those living in sub-Saharan Africa are at highest risk. The WHO African Region is severely affected, as nearly $80 \%$ of malaria cases and $90 \%$ of deaths are likely to occur here. Children below the age of five years and gravid women are most harshly affected. It has been estimated that about 50 million women of pregnancy age are at the risk of malaria each year. Pregnant women are more susceptible as compared to non-pregnant women, particularly in first and second pregnancy [11].

It is intriguing to note that malaria was recognized as the third reason of HIV-related morbidity in Africa [12]. Any kind of interaction between HIV infection and malaria may have potentially important public health implications [13]. However, because of a enormous scale-up in malaria control programs by the WHO, as part of the Millennium Development Goals, the estimated incidence of malaria globally has reduced by $17 \%$ and malaria-specific mortality rates by $26 \%$ between 2000 and 2010 [14]. Out of 43 countries with ongoing malaria transmission in the African Region, 8 countries namely Algeria, Botswana, Cape Verde, Namibia, Rwanda, Sao Tome and Principe, South Africa and Swaziland and the island of Zanzibar, have achieved decrease in malaria admission rates by $75 \%$ [11].

\section{HUMAN MALARIA PARASITES}

Malaria in humans is caused by an apicomplexan protozoan parasite of genus, Plasmodium. Five species of Plasmodium that infect humans are Plasmodium falciparum, Plasmodium vivax, Plasmodium ovale, Plasmodium malariae and Plasmodium knowlesi. Of these, P. falciparum and $P$. vivax are the most prevalent species found in most endemic areas; whereas, $P$. malariae and $P$. ovale infections have sparse and restricted distribution $[15,16]$. P. knowlesi, a natural parasite of macaques, causes acute illness and deaths also in persons living in proximity to the monkeys $[17,18]$. Among these species, $P$. falciparum causes malignant malaria and is accountable for most malaria morbidity and almost all malaria mortality. However, in tropical and subtropical areas, $P$. vivax can equal $P$. falciparum as a source of community-wide morbidity [19]. $P$. vivax is the most widespread species outside Africa in Asia and South America; whereas, illness with $P$. malariae and $P$. ovale are usually minor $[20,21]$.

Until recently, it was thought that the malaria caused by $P$. vivax was clinically less severe than that associated with $P$. falciparum and rarely lethal, but various studies in Southeast Asia have shown that about $25 \%$ of patients with severe malaria have mono-infection and multi-drug resistant vivax has been identified as causative agent [19,22]. Long-lasting infections are caused by P. malariae, which can persist asymptomatically for years and even for a lifetime, if untreated [23]. Various species of Plasmodium differ morphologically, immunologically, in geographical distribution, relapse pattern and drug resistance etc. The biology of $P$. falciparum differs from $P$. vivax in relapse pattern, severity and less preference of reticulocytes for invasion [24]. The life-cycles of most of the malaria parasites are basically the same despite various differences affecting appearance and pathogenicity among various species [25].

\section{MALARIA TRANSMISSION}

Malaria is a vector-borne disease, which spreads by the female mosquitoes of genus Anopheles. Out of the 460 recognized species of Anopheles, 100 species can transmit malaria in humans [26]. Sometimes, it is transmitted by transfused blood from infected to healthy individuals, sharing infected needles, or from an infected gravid woman to her fetus. A number of factors, including the spread of drug-resistant parasites, the emergence of insecticide-resistant mosquito vectors and the absence of an efficient vaccine are responsible for the persistence of malaria. Along with these global warming, changing agricultural practices, and human migration are also major contributors [27,28]. Persons in Refugee camps exposed to malaria and other infectious diseases in their country of origin, after immigration to developed nations may act as important reservoirs and further accelerate the spread of malaria [29] 


\section{CLINICAL MANIFESTATIONS OF MALARIA}

Upon rupturing of infected erythrocytes, an unknown toxin is discharged in blood stream, resulting in production of cytokine response, responsible for clinical manifestations. The clinical manifestations in malaria infected persons include fever, anemia, malaise and splenomegaly, and are due to the asexual multiplication of merozoites in RBCs [30,31]. Disease produces a strain of repeated paroxysms, each having three stages-chills, followed by temperature and then sweating. Besides these, the patient may have severe headache, nausea and vomiting. Within duration of an hour or two, the fever increases and then, as the fever falls, a wetting sweat initiates and the patient feels very weak, exhausted and sleepy. The malaria symptoms appear after 10 to 16 days of infection and coincide with the rupturing of infected RBCs. The spectrum of severe pathology is broad during $P$. falciparum infection, and includes metabolic acidosis, cerebral malaria (CM), and severe malarial anemia (SMA), and it is usually accompanied by hypoglycemia, hypoxia and lactic acidosis due in part to the increased metabolic demands of the parasite and occasionally multi-organ system failure may result in comma and death [30,31]. Therefore, new approaches, such as proper diagnosis, vaccine development and discovery of novel therapeutic agents, are urgently needed to combat the disease.

\section{MALARIA AND ECONOMY}

Malaria is directly linked to socio-economic development and referred as both a disease of poverty and a cause of poverty. It exerts a huge economic load on endemic countries [27,32]. It is a well-known fact that annual economic growth in malaria endemic countries has historically been lower than in malaria free countries. According to economists, the malaria is responsible for a growth penalty of upto $1.3 \%$ per year in some African countries. Malaria destroys the capacities of individuals and hence the economic development of their countries. Mocumbi (2004) reported that the disease delays the development of sub-Saharan African countries at a cost of at least US\$ 12,000 million per year [33]. Poverty and childhood mortality cannot be reduced in these countries without adequate malaria control measures. But, the problem of malaria control in these countries is strengthened by perilous socioeconomic conditions and insufficient health-care infrastructures. Population growth, fertility, saving and investment, worker productivity, absence, premature mortality and medical costs are different channels by which malaria affects development [27].

\section{Acknowledgements}

Authors acknowledge the financial assistance provided by the University Grants Commission (UGC), New Delhi as RFSMS under UGC-CAS programme to Anil Pawar.

\section{References:}

[1] P.L. Alonso, Malaria: deploying a candidate vaccine (RTS,S/AS02A) for an old scourge of humankind, Int. Microbiol. 9 (2006) 83-93.

[2] A. Laveran, “Traite des fievres palusters”, Doin, Paris, 1884.

[3] P. Manson, On the nature and significance of the crecentic and flagellated bodies in malarial blood, Br. Med. J2 (1894) 1306-1308.

[4] R. Ross, "Report on the cultivation of Proteosoma labbe in Grey Mosquitoes". Government press, Calcutta, 1898.

[5] B. Grassi, A. Bignami, G. Bastianelli, Cido evolution delle semilune nell Anopheles claviger, Atti. Soc. Studi. Malar. 1 (1899) 14.

[6] G. Bastianelli, A. Bignami, Sullo suilappo dei parassiti della terzana nell Anopheles claviger, Atti. Soc. Studi. Malar. 1 (1899) 28-49. 
[7] G. Raffaele, Un Ceppo italiano di Plasmodium elongatum, Riv. Malariol. 13 (1934) 3-8.

[8] H.E. Shortt, P.C.C. Garnham, The pre-erythrocytic development of P. cyanomolgi and P. vivax, Trans. R. Soc. Trop. Med. Hyg. 41 (1948) 785-795.

[9] H.E. Shortt, N.H. Feirley, G. Covell, P.G. Shute, P.C.C. Garnham, The pre-erythrocytic stages of Plasmodium falciparum, Trans. R. Soc. Trop. Med. Hyg. 44 (1951) 405-419.

[10] C.J. Murray, L.C. Rosenfeld, S.S. Lim, K.G. Andrews, K.J. Foreman, D. Haring, N. Fullman, M. Naghavi, R. Lozano, A.D. Lopez, Global malaria mortality between 1980 and 2010: a systematic analysis, Lancet. 379 (2012) 413-431.

[11] WHO, World malaria report, 2012, WHO press, Geneva, ISBN 978924156453 3, 2012.

[12] C.B. Holmes, E. Losina, R.P. Walensky, Y. Yazdanpanah, K.A. Freedberg, Review of human immunodeficiency virus type 1-related opportunistic infections in sub-Saharan Africa, Clin. Infect. Dis. 36 (2003) 652-662.

[13] C. Flateau, G. Le Loup, G. Pialoux, Consequences of HIV infection on malaria and therapeutic implications: a systematic review, Lancet Infect. Dis. 11 (2011) 541-556.

[14] WHO, World malaria report, 2011, WHO press, Geneva, ISBN 978924156440 3, 2011.

[15] M.T. Al-Maktari, H.K. Bassiouny, Z.S. Al-Hamd, A.M. Assabri, A.G. El-Massry, H.Z. Shatat, Malaria status in Al-Hodeidah Governorate, Yemen: malariometric parasitic survey and chloroquine resistance P. falciparum local strain, J. Egypt. Soc. Parasitol. 33 (2003) 361-372.

[16] K.M. Lekweiry, M.O. Abdallahi, H. Ba, C. Arnathau, P. Durand, J.F. Trape, A.O. Salem, Preliminary study of malaria incidence in Nouakchott, Mauritania, Malar. J. 8 (2009) 92-98.

[17] J. Cox-Singh, T.M. Davis, K.S. Lee, S.S. Shamsul, A. Matusop, S. Ratnam, H.A. Rahman, D.J. Conway, B. Singh, Plasmodium knowlesi malaria in humans is widely distributed and potentially life threatening, Clin. Infect. Dis. 46 (2008) 165-171.

[18] J. Cox-Singh, B. Singh, Knowlesi malaria: newly emergent and of public health importance?, Trends. Parasitol. 24 (2008) 406-410.

[19] R.N. Price, N.M. Douglas, N.M. Anstey, New developments in Plasmodium vivax malaria: severe disease and the rise of chloroquine resistance, Curr. Opin. Infect. Dis. 22 (2009) 430-435.

[20] J.-M. Kang, M. Sung-Ung, K. Jung-Yeon, C. Shin-Hyeong, K. Lin, S. Woon-Mok, K. TongSoo, N. Byoung-Kuk, Genetic polymorphism of merozoite surface protein-1 and merozoite surface protein-2 in Plasmodium falciparum field isolates from Myanmar, Malar. J. 9 (2010) 131.

[21] M.M. Stevenson, R. Ing, F. Berretta, J. Miu, Regulating the adaptive immune response to blood-stage malaria: role of dendritic cells and $\mathrm{CD}^{+}{ }^{+} \mathrm{Foxp}^{+}$regulatory T cells, Int. J. Biol. Sci. 7 (2011) 1311-1322.

[22] E. Tjitra, N.M. Anstey, P. Sugiarto, N. Warikar, E. Kenangalem, M. Karyana, D.A. Lampah, R.N. Price, Multidrug-resistant Plasmodium vivax associated with severe and fatal malaria: a prospective study in Papua, Indonesia, PLoS. Med. 5e (2008) 128.

[23] K.E. Kester, J.F. Cummings, O. Ofori-Anyinam, C.F. Ockenhouse, U. Krzych, P. Moris, R. Schwenk, R.A. Nielsen, Z. Debebe, E. Pinelis, L. Juompan, J. Williams, M. Dowler, V.A. Stewart, R.A. Wirtz, M.C. Dubois, M. Lievens, J. Cohen, W.R. Ballou, D.G. Heppner, Randomized, doubleblind, phase 2a trial of falciparum malaria vaccines RTS,S/AS01B and RTS,S/AS02A in malarianaive adults: safety, efficacy, and immunologic associates of protection, J. Infect. Dis. 200 (2009) $337-346$.

[24] S.K. Prajapati, H. Joshi, V.K. Dua, Antigenic repertoire of Plasmodium vivax transmissionblocking vaccine candidates from the Indian subcontinent, Malar. J. 10 (2011) 111. 
[25] H.K. Heggenhouegen, V. Hackethal, P. Vivek, The behavioural and social aspects of malaria and its control, UNDP/World Bank/WHO Special Programme for Research and Training in Tropical Diseases (TDR), 2003.

[26] K. Raghavendra, T.K. Barik, B.P.N. Reddy, P. Sharma, A.P. Dash, Malaria vector control: from past to future, Parasitol. Res. 108 (2011) 757-779.

[27] J. Sachs, P. Malaney, The economic and social burden of malaria, Nature. 415 (2002) 680-685.

[28] M.F. Good, Vaccine-induced immunity to malaria parasites and the need for novel strategies, Trends. Parasitol. 21(2005) 29-34.

[29] C.E. Matisz, P. Naidu, S.E. Shokoples, D. Grice, V. Krinke, S.Z. Brown, K. KowalewskaGrochowska, S. Houston, S.K. Yanow, Post-arrival screening for malaria in asymptomatic refugees using real time PCR, Am. J. Trop. Med. Hyg. 84 (2011) 161-165.

[30] K. Artavanis-Tsakonas, J.E. Tongren, E.M. Riley, The war between the malaria parasite and the immune system: immunity, immunoregulation and immunopathology, Clin. Exp. Immunol. 133 (2003) 145-152.

[31] M.B.B. McCall, R.W. Sauerwein, Interferon gamma-central mediator of protective immune responses against the pre-erythrocytic and blood stage of malaria, J. Leukoc. Biol. 88 (2010) 11311143.

[32] A. Teklehaimanot, G.C. McCord, J.D. Sachs, Scaling up malaria control in Africa: an economic and epidemiological assessment, Am. J. Trop. Med. Hyg. 77 (2007) 138-144.

[33] P. Mocumbi, Plague of my people, Nature. 430 (2004) 925. 